\title{
Metodologia de pesquisa para construção de modelo de apoio à decisão na gestão de recursos naturais em empreendimentos turísticos ${ }^{1}$
}

\author{
Research methodology for building a decision support model for natural \\ resources management in tourist resorts
}

\author{
João Miguel Mendes Silveira, Lúcio José Sobral Cunha
}

\section{RESUMO}

Dentro do sistema turístico, o setor do alojamento é responsável por ações com grandes repercussões ambientais no território e nas suas populações. Em Portugal e no Brasil, assim como na generalidade dos destinos turísticos, o aumento sazonal da procura agrava a pressão sobre os recursos naturais e a sua gestão. A procura de sustentabilidade dos alojamentos turísticos é hoje apoiada por inúmeros sistemas de certificação, mas a comunidade científica aponta a falta de objetivos mínimos mais ambiciosos, de priorização dos critérios e de quantificação dos impactos em função do contexto. Dito doutra forma, faltam ferramentas de apoio à decisão que agrupem as soluções práticas existentes e orientem as etapas de planejamento e gestão dos empreendimentos turísticos com vista a um aumento da sustentabilidade ambiental. Neste artigo, apresentar-se-á um projeto de pesquisa que se propõe a estudar opções na gestão de recursos naturais, a seguir por empreendimentos turísticos, com vista a incrementar uma utilização racional e sustentável dos recursos. O projeto assenta na construção de um modelo computacional que tem por base a recolha de dados acerca das soluções técnicas e tecnologias de gestão diária dos recursos e das características médias de utilização de recursos pelos alojamentos turísticos, em função das suas características, bem como da disponibilidade de recursos naturais no território envolvente aos empreendimentos. Para estudos de casos, escolher-seão empreendimentos turísticos que traduzam realidades distintas tanto ao nível dos territórios e dos recursos disponíveis, como do tipo de turistas e das práticas habituais de gestão. Serão selecionados empreendimentos situados em regiões turísticas portuguesas e brasileiras que possam servir de exemplos paradigmáticos de gestão. Pretende-se, como objetivo final, que o modelo seja funcional a partir das realidades estudadas e que, incorporando a capacidade das soluções existentes mais eficientes, possa ser aplicado a novos casos em análise.

PALAVRAS-CHAVE: Gestão de Recursos Naturais; Empreendimentos Turísticos; Modelo de Apoio à Decisão. 
Metodologia de pesquisa para construção de modelo de apoio à decisão na gestão de recursos naturais em empreendimentos turísticos

\begin{abstract}
Within the tourism system, the accommodation sector is responsible for actions with great environmental impacts in the territory and its populations. In Portugal and Brazil, as in most tourist destinations, the seasonal increase in demand exacerbates the pressure on the natural resources and their management. The demand for sustainability in tourist accommodations has now the supported of several certification schemes, but the scientific community points to the lack of more ambitious minimum goals, the lack of prioritizing criteria and the absence of impact quantifying methods according to local context. Put otherwise, there is a lack of decision support tools for bringing together existing practical solutions and guiding decisions on planning and management for environmental sustainability at tourism resorts. This article presents a research project that aims to study different choices employable for managing natural resources at tourism resorts, in order to increase its efficiency and sustainability. The core of this project is the building of a computer model, based on the collection of data on technical solutions and technologies for the daily management of resources and on the average resource expenditure by tourist and accommodation's characteristics, as well as on the local resources abundance within the surrounding environment. For the case studies, there will be selected tourist ventures that reflect different realities in terms of territory and resources availability, as well as type of tourists and management practices. Selected projects will be located in Brazilian and Portuguese tourist areas that can serve as paradigmatic examples of management. It is intended, as a final goal, that the model be functional based on the studied venues and that, by incorporating the more efficient solutions, can be applied for new cases analysis.
\end{abstract}

KEYWORDS: Natural Resources Management; Tourism Resorts; Decision Support Model.

\title{
Introdução
}

O turismo, atividade que promove o progresso das regiões e é desejada pelas suas populações, conduz muitas vezes a diversos problemas ambientais, quando o seu planejamento ou gestão não se realizam de forma adequada ao seu contexto de implementação (ROSS, 1999; HALPENNY, 2001).

As políticas de ordenamento turístico tem evoluído positivamente ainda que subsistam impactos negativos continuados sobre o território (DIAS; POLETTE; CARMO, 2008). Apesar da adesão crescente a estratégias de turismo sustentável, o aumento da população nas zonas costeiras e o aumento sazonal da procura turística mantêm e intensificam a pressão demográfica sobre a conservação dos recursos naturais (BUCKLEY, 2001; TIMAH et al., 2008). Existem ainda muitos locais no planeta onde são frequentes os problemas relacionados com o uso de recursos naturais básicos como a água ou a energia e onde há escassez pontual ou generalizada de bens essenciais. Nestas situações o turismo, quando planejado de forma inadequada, acaba por ser mais um problema ou, pelo menos, 
por contribuir para estes problemas, pressionando para a instalação de infraestruturas inadequadas às necessidades locais e/ou interferindo na estrutura social e na distribuição de recursos naturais. A aplicação de práticas mais sustentáveis deverá ser, assim, uma prioridade a todos os níveis de atuação e setores de atividades turísticas (LIBURD et al., 2007).

Dentro do sistema turístico, o setor do alojamento é responsável pelas ações com maiores repercussões ambientais no território e nas suas populações. Existe uma cada vez maior proliferação de empreendimentos turísticos geridos de forma não sustentável para a conservação dos recursos naturais da região em que se inserem. Os seus impactos, positivos e negativos, directos ou indirectos, imediatos ou a prazo, são transversais a todos setores da atividade humana e afetam tanto o patrimônio construído como o natural (HUNTER; SHAW, 2007).

As boas práticas de sustentabilidade no turismo em geral, e nos alojamentos turísticos em particular, não representam apenas benefícios para a preservação e valorização dos recursos do território, ou para as populações e economia locais, mas também para a atração de turistas (GOSSLING, 2002).

A sustentabilidade nos alojamentos turísticos é hoje apoiada por inúmeros sistemas de certificação que lhes conferem rótulos de qualidade utilizados muitas vezes em campanhas de publicidade e marketing (GRAULICH, 2006). Estes mecanismos de apoio à decisão e de aferição da sustentabilidade (FRAME; BROWN, 2008) são muito variados em âmbito e objetivos. Os seus critérios diferem muito, mesmo entre os sistemas de Turismo Sustentável ou de Ecoturismo e Eco-Hotéis (JANÉR, 2009). Em termos de gestão ambiental os critérios privilegiam a adoção de fontes de energias renováveis, eficiência energética, poupança de água, tratamento de efluentes e de resíduos alimentares e não alimentares, assim como medidas de conservação da biodiversidade (OSLAND; MACKOY, 2004). No entanto, a comunidade científica e técnica continua a apontar a falta de objetivos mínimos mais ambiciosos, de priorização dos critérios e de quantificação dos impactos ambientais em função do contexto, tal como é apresentado por Janér (2009, slide 25) como uma das críticas dos cépticos: "os critérios são muitos, sem ordem de importância e, dependendo do destino, as prioridades podem ser diferentes". Para se considerar o impacto final de determinado processo de gestão ambiental é pois fundamental a sua contextualização nas dinâmicas territoriais e na disponibilidade de recursos naturais locais (STIJNS, 2006).

Existem muitas soluções inovadoras e tradicionais de gestão de recursos naturais nos empreendimentos turísticos, algumas ainda não descritas sistematicamente, que promovem uma utilização mais eficiente. Estas soluções foram desenvolvidas, adaptadas ou recuperadas para lidar com a escassez de determinado recurso e/ou para reduzir grandemente a dependência externa e 
Metodologia de pesquisa para construção de modelo de apoio à decisão na gestão de recursos naturais em empreendimentos turísticos

aumentar a auto-suficiência. Apesar de surgirem geralmente da necessidade de resposta à privação de um dado recurso, ou em virtude de uma política ou filosofia específica de desenvolvimento, são aplicáveis a qualquer contexto, conseguindo atingir graus de eficiência e poupança superiores em relação aos preconizados como suficientes pelas certificações existentes. Muitas delas permitem a coleta dos recursos pretendidos o mais próximo possível do destino na cadeia de consumo e possibilitam o armazenamento e reutilização dos mesmos (AYALA, 1995). Os exemplos práticos mais conhecidos destas soluções vão desde o aproveitamento de águas pluviais, o reaproveitamento de águas cinzentas para rega, a aplicação de redutores de caudal em torneiras, o aquecimento solar de águas sanitárias, a produção de energia por diversas fontes renováveis, a utilização de equipamentos de maior eficiência energética, ao reaproveitamento de resíduos alimentares para adubar produção alimentar local. Soluções com o mesmo intuito mas de conhecimento mais disperso são, por exemplo, sistemas de extração de água por força eólica e/ou solar, técnicas de poupança de água de rega pela minimização da evapotranspiração, técnicas de aumento da produtividade agrícola pelo aumento da biodiversidade (e.g. permacultura), técnicas biológicas de purificação de água, fornos solares e formas de produção de energia a partir de biomassa e outros combustíveis sólidos (e.g. óxido sólido). Existirão sem dúvida outras soluções a encontrar e catalogar, as quais constituem um dos objetivos deste projeto de pesquisa, salvaguardando que o foco de atenção recai de forma exclusiva, não sobre as opções de construção, mas sobre as soluções usadas na gestão diária de recursos naturais.

Considerando um empreendimento turístico existente como um sistema aberto, de acordo com os postulados da Teoria dos Sistemas (HARTMANN, 2005), a intervenção sobre a conservação dos recursos naturais necessários ao seu funcionamento diário pode acontecer nos momentos de captação, consumo, reutilização e devolução ao ambiente. Implementando várias das soluções acima referidas em empreendimentos turísticos, conseguir-se-á responder mais facilmente a uma existente ou eventual escassez de determinado recurso e, sobretudo, ajudar a preservar os recursos naturais locais em quantidade e qualidade, minimizando os impactos do setor do alojamento no território e nas populações (WOOD, 2002).

Convém, no entanto, referir que a disponibilidade ou o acesso aos recursos naturais é condicionada por diferentes contextos geográficos, bioclimáticos e mesmo de contexto temporal. Assim, mediante a insolação, a pluviosidade, o tipo de solo, a disponibilidade de água no subsolo, a biodiversidade, a população residente ou o aumento sazonal da população, entre outros, as exigências de recursos naturais serão diferentes e, como tal, as possibilidades vantajosas de integração de técnicas e tecnologias que façam melhor a sua gestão serão também diferentes. 
Decisões informadas serão o principal contributo para a sustentabilidade na gestão de recursos naturais em empreendimentos turísticos. Mas faltam ainda ferramentas para empreendedores que agrupem soluções práticas e orientem nas decisões de planejamento e gestão com vista à sustentabilidade e à sua melhoria contínua (WEAVER; LAWTON, 2007).

No seio da avaliação de imóveis surgiram outras ferramentas de apoio à decisão e de aferição de sustentabilidade aplicáveis a empreendimentos turísticos. Como exemplo das mais reputadas temos o BREEAM e o LEED que avaliam os processos e o resultado final mas não incidem sobre a eficiência de cada solução técnica (HAAPIO; VIITANIEMI, 2008). Por outro lado existem ferramentas que avaliam essa eficiência (Análise do Ciclo de Vida) mas são focadas em produtos segmentados e não fornecem uma avaliação global aplicável ao contexto deste trabalho (SINGH et al., 2012). Em nenhum dos casos a análise tem em conta as especificidades do local de implantação em termos de disponibilidade de recursos naturais (NESS et al., 2007; SINGH et al., 2012).

O projeto de pesquisa que se apresenta neste trabalho propõe-se a avaliar as diferentes escolhas possíveis a nível das soluções de gestão de recursos naturais a empregar por empreendimentos turísticos, com vista a incrementar a sustentabilidade na gestão desses recursos. Para tal será usado um software de modelação para construir um modelo computacional, que simule a realidade estudada, tendo por base a recolha de dados acerca das soluções técnicas e tecnologias de gestão diária dos recursos e das características médias de utilização de recursos pelos alojamentos turísticos. Esta análise será enquadrada com o meio envolvente aos empreendimentos, de forma a possibilitar a aferição da sustentabilidade ambiental, através de indicadores de abundância de recursos locais.

Os métodos de recolha de dados que serão apresentados em detalhe neste trabalho tem como propósito único o fornecimento de valores fidedignos ao software de modelação. O modelo computacional, sendo uma representação simplificada da realidade restrita do sistema em estudo, um empreendimento turístico inserido num território, deverá prever diferentes comportamentos de resultados em função de diferentes valores iniciais e das soluções adotadas. A partir desta ferramenta será possível comparar empreendimentos distintos.

A Figura 1 apresenta um diagrama conceitual do tema em estudo. Este diagrama conceitual, ao esquematizar o tema em estudo, constitui igualmente um esboço empírico simplista dos elementos constituintes e respetivos fluxos de elementos que serão introduzidos para análise na ferramenta metodológica. (LAWSON, 2006). 
Metodologia de pesquisa para construção de modelo de apoio à decisão na gestão de recursos naturais em empreendimentos turísticos

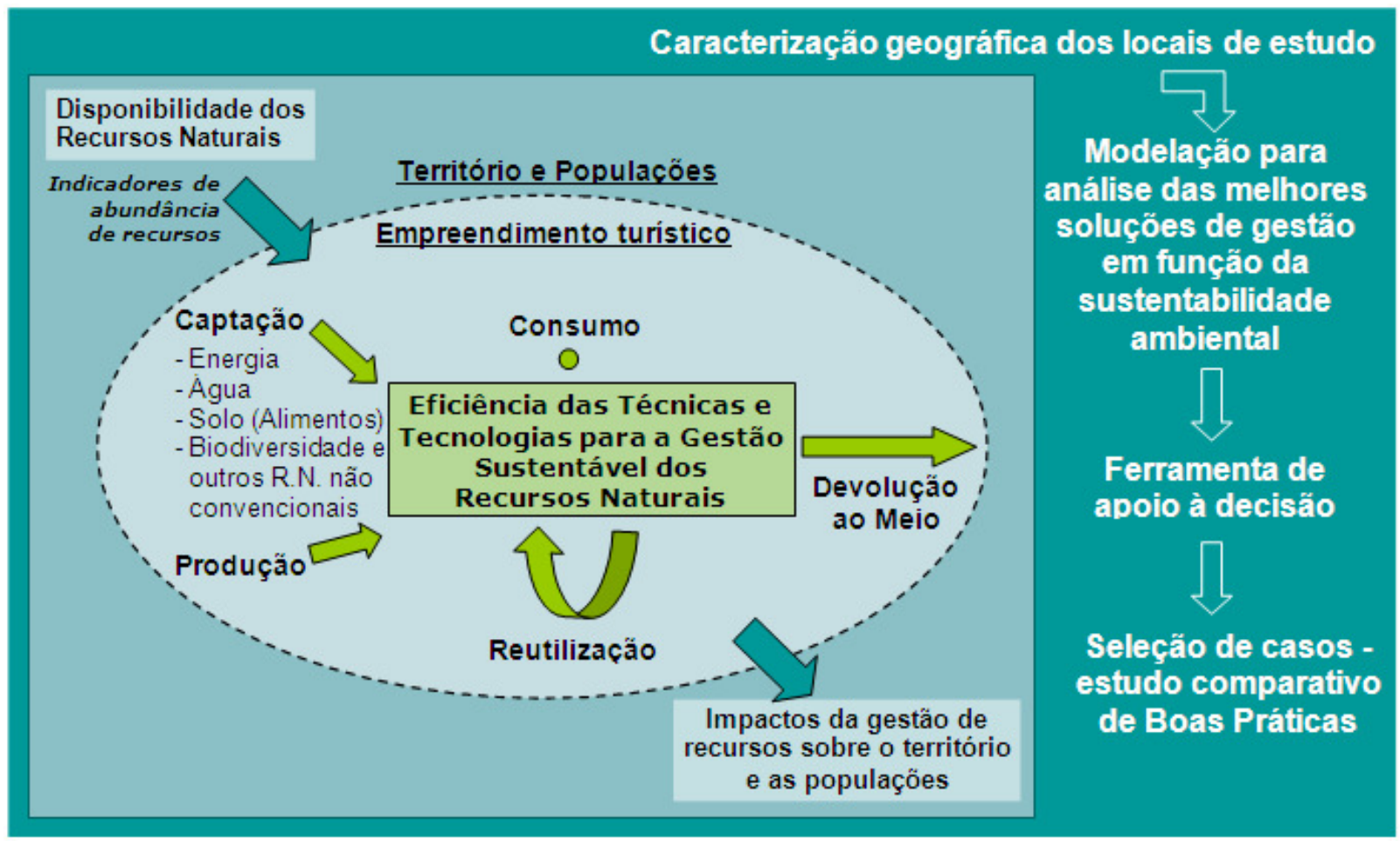

Figura 1: Sustentabilidade na gestão de recursos naturais pelos empreendimentos turísticos: diagrama conceitual do tema em estudo e objetivos.

Figure 1: Sustainability in natural resource management for tourism projects:conceptual diagram of the study theme and objectives.

\section{Operacionalização da Pesquisa}

\section{Pressupostos e Pergunta-Pesquisa}

Analisando a realidade alvo da proposta de estudo, e tendo em conta o referido até este ponto, surge a pergunta:

- será possível criar um modelo (funcional, preditivo e que resulte numa ferramenta de apoio à decisão), a partir de realidades a estudar e que, incorporando a capacidade das soluções sustentáveis mais eficientes, faça a sua integração e dimensionamento para novos casos em análise, de forma a responder ao consumo de recursos naturais com um impacto ambiental reduzido em função das características do empreendimento e do território?

\section{Objetivos}

Desenvolvendo-se, portanto, em torno do tópico da sustentabilidade da gestão dos recursos naturais necessários à operação diária de empreendimentos turísticos, a pesquisa proposta tem como objetivos:

- identificar e caracterizar o território e os recursos naturais da área de implementação dos empreendimentos turísticos; 
- identificar e sistematizar padrões e valores médios de utilização dos recursos naturais em empreendimentos turísticos;

- avaliar o impacto ambiental para a região de uma utilização não sustentável;

- identificar, caracterizar e quantificar em termos de eficiência as melhores soluções ao nível de técnicas e tecnologias de gestão da captação, consumo e reutilização, que respondam positivamente à escassez dos recursos naturais;

- criar um modelo computacional que simule a realidade em análise (incorporando de forma interdependente e funcional as variáveis em estudo) e que calcule um índice de sustentabilidade de gestão de recursos naturais locais por características de empreendimentos turísticos;

- desenvolver uma ferramenta de apoio à decisão no planejamento e gestão de empreendimentos turísticos para a sustentabilidade máxima na gestão de recursos naturais, facilitando a escolha e o dimensionamento das melhores soluções técnicas, que possibilite análises comparadas entre empreendimentos (a efetivar para estudos de caso a selecionar em Portugal e no Brasil).

\section{Hipóteses já formuladas}

A seguir apresentam-se as hipóteses e as variáveis já delineadas. De ressalvar que, fruto da revisão bibliográfica ainda em curso, estas poderão ainda sofrer alterações.

- As técnicas e tecnologias de gestão ambiental de alojamentos turísticos, adaptadas à escassez de recursos locais, são replicáveis e benéficas para a sustentabilidade de qualquer empreendimento, permitindo ir além do constante nos parâmetros das certificação e avaliação existentes.

- É possível criar um modelo funcional de previsão de sustentabilidade de gestão de recursos naturais para alojamentos turísticos, em função das características do empreendimento, dos métodos e técnicas de gestão e da disponibilidade regional dos recursos.

- A partir do modelo computacional funcional (que explora impactos de opções de gestão) é possível criar uma ferramenta prática de apoio à decisão que facilite a inclusão das melhores técnicas e tecnologias para uma sustentabilidade máxima na gestão diária de recursos naturais pelos empreendimentos turísticos.

\section{Variáveis já definidas para análise}

- Tipologia dos recursos naturais de consumo diário, de $1^{\text {a }}$ ordem (captação) e de $2^{a}$ ordem (reaproveitamento), que são alvo de gestão diária num empreendimento turístico.

- Padrões de quantidade e qualidade de recursos naturais que os 
Metodologia de pesquisa para construção de modelo de apoio à decisão na gestão de recursos naturais em empreendimentos turísticos

empreendimentos necessitam em função da dimensão, do número médio de clientes e das opções de construção e de gestão.

- Disponibilidade e qualidade dos recursos naturais locais.

- Eficiência das soluções técnicas e tecnologias existentes, artesanais e/ou inovadoras, que respondam positivamente à escassez de cada recurso analisado e promovam uma sustentabilidade máxima pela sua utilização.

- Viabilidade e impactos no ciclo de vida de cada recurso que advêm da integração simultânea e caso-a-caso das várias soluções sustentáveis encontradas.

\section{Definição operacional dos conceitos}

Os conceitos utilizados do ponto de vista operacional serão explicitados a seguir. São apresentadas sob um ponto de vista genérico sendo facilmente particularizadas para o tema em estudo.

- Sustentabilidade: o relatório "Brundtland" definiu Desenvolvimento Sustentável como: "(...) development, which implies meeting the needs of the present without compromising the ability of future generations to meet their own needs (...)" (WCED, 1987). Desta definição advém o conceito de sustentabilidade aplicável a qualquer ação humana, como ações planejadas, geridas e monitorizadas de forma a salvaguardar o estado de conservação dos recursos e a preservar a qualidade de vida das populações presentes e futuras. Adicionalmente gerou-se a discussão entre a validade ou não de comutações entre as vertentes ambiental, sóciocultural e econômica dando origem às distinções entre sustentabilidade fraca e forte. Para o presente trabalho, para fortalecer o distanciamento de práticas de gestão associadas à falta de sustentabilidade, usa-se como base conceitual a sustentabilidade forte, onde deixam de ser consideradas possíveis as trocas ou compensações entre as várias vertentes da sustentabilidade (NESS et al., 2007; GASPARATOS, 2010).

- Turismo sustentável: integrado com o conceito anterior, turismo sustentável pode ser definido como um turismo de baixo impacto no ambiente e cultura locais, que estimule o emprego junto da população local e que, no geral, pretenda garantir que 0 desenvolvimento desencadeie impactos $e$ experiências positivas junto das populações locais, dos operadores turísticos e dos turistas (WTO, 2004). O presente trabalho usará este conceito mas, dados os seus objetivos, centrar-se-á na componente ambiental.

- Território: refere-se a uma área delimitada sob a posse de uma entidade biológica ou cultural. Especificando para o contexto da Geografia, o conceito de território é trabalhado como o resultante da interacção 
sociedade/espaço natural.

- Modelação computacional: trata-se de um método de cálculo (muito diversificado em aplicações) assente na matemática diferencial e, mais recentemente, na programação. Possibilita analisar um elevado número de variáveis em sistemas complexos. Usa os métodos numéricos e de linguagem de programação com vista a efetivar simulações através de projeções temporais e/ou espaciais de fluxos de elementos (HARTMANN, 2005; LAWSON, 2006).

- Modelo de apoio à decisão: um modelo de apoio à decisão pode ser conceitual, matemático ou misto e tem como finalidade permitir definir entre várias soluções qual a mais indicada para um determinado contexto. Para a construção de modelos é necessária uma análise estruturada dos problemas com vista a uma sistematização de todas as vertentes envolvidas nos processos de decisão (CUNHA et al., 2002).

- Ferramenta de apoio à decisão: as ferramentas de apoio à decisão baseiam -se em referenciais normativos e estabelecem linhas de conduta para tomadas de decisão, normalmente consecutivas e consequentes, em função dos objetivos e dos cenários abrangidos.

- Recursos Naturais: recursos naturais são bens da natureza com utilidade para o ser humano, não sendo passíveis de ser produzidos por este. São de tipologias diversas e em número elevado, alguns possuem ciclos de vida podendo ser reutilizados. Para simplificar a sua compreensão são catalogados tendo em conta o seu conteúdo (geológico, pedológico, hídrico, biológico e climático), disponibilidade (renováveis ou não renováveis) ou importância estratégica (PEREIRA; ZÊZERE; MORGADO, 2005).

- Gestão de Recursos Naturais: Gestão é, na sua essência, um processo que consiste em planear, organizar, motivar e controlar, para que determinado objetivo possa ser cumprido, dentro de um determinado contexto físico, humano e temporal (SWARBROOKE, 1999). A gestão de recursos naturais corresponde portanto aos princípios de gestão aplicados sobre os recursos naturais. No caso dos empreendimentos turísticos estão envolvidos os seguintes recursos naturais: energia, água, produtos alimentares, solo e biodiversidade).

- Técnicas e tecnologias de gestão sustentável de recursos naturais são soluções técnicas, materiais ou ferramentas que operam na recolha, tratamento, consumo, reaproveitamento e conservação de recursos naturais, e que exibem maior adaptação que as soluções comuns a promover a preservação dos recursos.

- Empreendimentos Turísticos: segundo definição disponibilizada pela Turismo de Portugal (s.d.), são empreendimentos turísticos: “(...) os 
Metodologia de pesquisa para construção de modelo de apoio à decisão na gestão de recursos naturais em empreendimentos turísticos

Figura 2 ilustra a tipologia de dados a inserir e refere a padronização de unidades a utilizar.

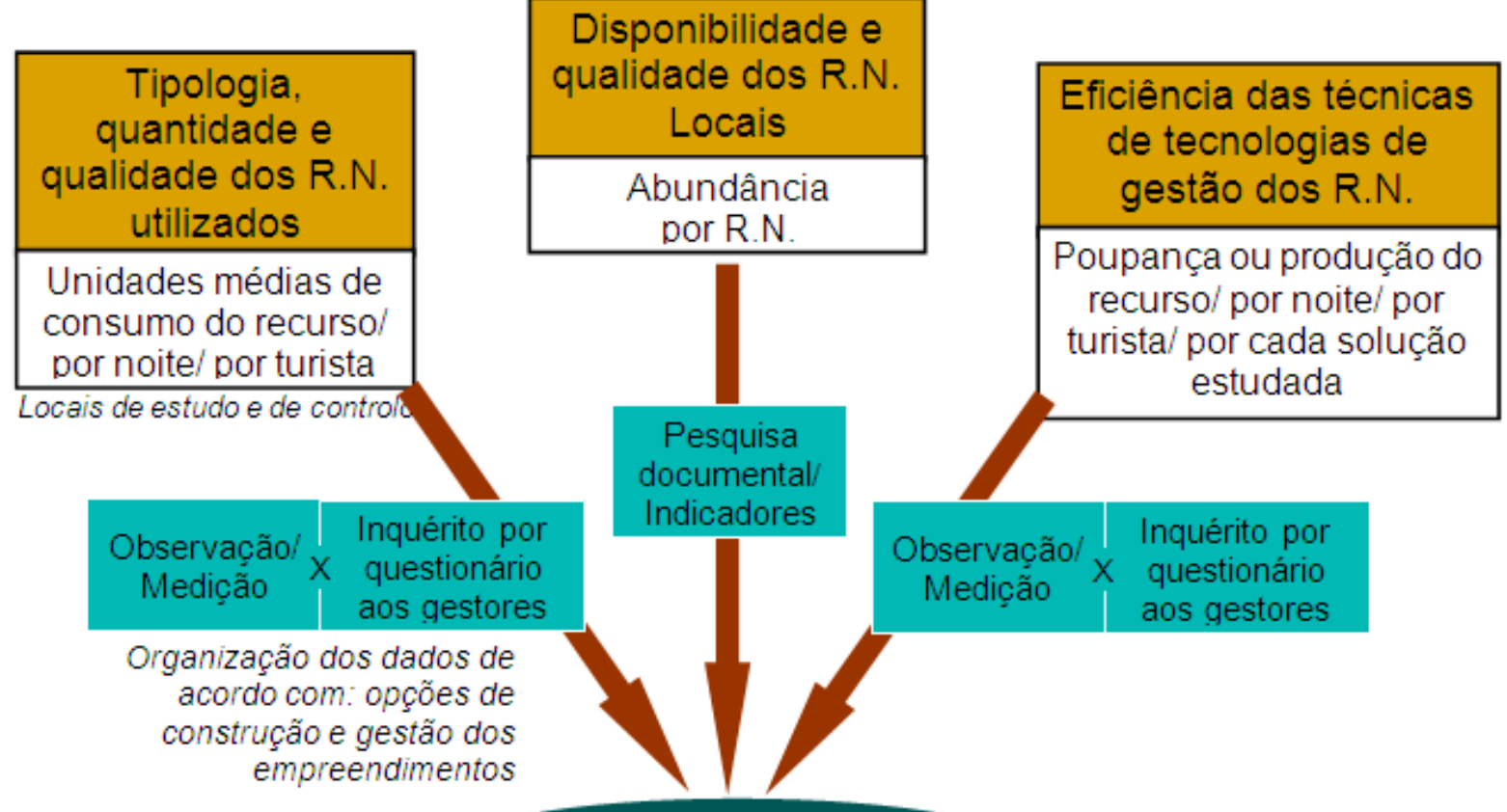

Modelacão computacional

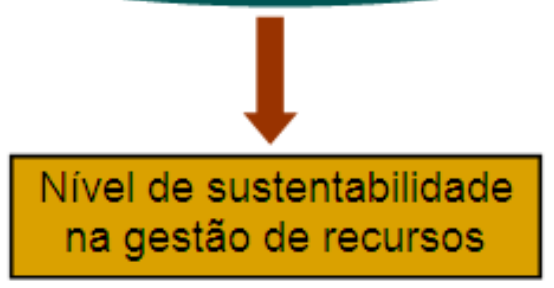

Figura 2: Esquema conceitual dos métodos de recolha e tratamento dos dados.

Figure 2: Conceptual framework of the methods of collecting and processing the data.

Ao longo da execução do plano de trabalhos serão utilizados os seguintes métodos de recolha e tratamento de dados de acordo com as tipologias de dados:

- Tipologia, quantidade e qualidade dos recursos naturais utilizados pelos empreendimentos nos locais em estudo e nos de controle - Observação estruturada, observação estruturada com medição e inquérito estruturado aos gestores dos empreendimentos. Com vista a identificar e sistematizar padrões e valores médios de utilização dos recursos, os valores obtidos serão segmentados segundo a dimensão do empreendimento, taxa de ocupação e as diversas opções de construção e de gestão. Os dados quantitativos serão tratados em unidades médias (média simples) de consumo do recurso em causa por noite, turista e características do 
empreendimento.

- Disponibilidade e qualidade dos recursos naturais locais da região onde se insere o empreendimento - Pesquisa documental. Esta recolha de dados tem por fim identificar indicadores simples e sistematizar condicionalismos e impactos que assistam ao funcionamento do modelo em termos de contextualização no território.

- Identificar, caracterizar e quantificar o contributo de cada solução inovadora ou tradicional - Observação estruturada, observação estruturada com medição e inquérito estruturado aos gestores dos empreendimentos. Após a descrição qualitativa das técnicas e ferramentas encontradas (condições de operação, incluindo confiabilidade e resposta a variações sazonais), serão recolhidos os dados quantitativos de desempenho: valores de produção, consumo, reutilização e custos de construção ou de aquisição e manutenção. Os dados quantitativos serão tratados por média simples de poupança ou produção do recurso por noite, turista e cada solução estudada.

No final, os dados recolhidos por questionários (após validação em termos de confiabilidade das respostas) e por observações serão organizados por tipologia e agrupados com vista à obtenção de médias simples (de acordo com a padronização de unidades definida), após eliminar casos únicos ou especiais. Os dados recolhidos por pesquisa documental serão organizados e sistematizados para que as respostas possíveis aos indicadores sejam facilmente revertidas em categorias de resultados de abundância de recursos naturais específicas para cada tipo, e sem desvirtualizar o rigor de funcionamento dos indicadores. Fruto destes tratamentos resultarão os dados numéricos e categoriais a introduzir no software de modelação computacional.

Adicionalmente, para cada região alvo de estudo, serão recolhidos dados de caracterização geográfica a partir de fontes secundárias, com vista a enquadrar as condições do meio no estudo comparativo final.

\section{Análise dos Dados}

O software de modelação a usar será, em princípio, o STELLA ${ }^{\circledR}$. As vantagens deste software em relação aos demais residem da sua reputação de longa data como ferramenta confiável e de interface amigável para o utilizador.

Para a construção do modelo serão identificados e inseridos todos os elementos do sistema obtidos a partir dos seguintes fatores: características do empreendimento, recursos utilizados, recursos disponíveis e eficiência das melhores soluções sustentáveis. Estes elementos serão organizados em 
Metodologia de pesquisa para construção de modelo de apoio à decisão na gestão de recursos naturais em empreendimentos turísticos

estabelecimentos que se destinam a prestar serviços de alojamento, mediante remuneração, dispondo, para o seu funcionamento, de um adequado conjunto de estruturas, equipamentos e serviços complementares".

\section{Identificação dos locais de recolha de dados}

Haverá um particular cuidado na definição do tipo e quantidade de empreendimentos a estudar. A identificação dos locais terá por base uma amostragem não probabilística por seleção de casos típicos (RAMOS, 2010). Em termos geográficos amplos a pesquisa será planeada para os locais que se mostrem mais relevantes, sendo à partida considerada a região do nordeste do Brasil, onde a escassez de alguns recursos se alia a um rápido desenvolvimento turístico.

As características preferenciais dos locais de estudo no Brasil e em Portugal, para comparação, apontam para locais que:

- apresentem um fluxo turístico contínuo;

- estejam inseridos em regiões com escassez de recursos naturais;

- possuam, além da área construída, terrenos rurais ou naturais (fora dos perímetros urbanos);

- apresentem soluções técnicas, materiais e/ou ferramentas inovadoras na gestão ambiental e/ou recuperem práticas tradicionais de recolha $\mathrm{e}$ tratamento dos recursos naturais, estando mais adaptadas que as soluções comuns para lidar com períodos de escassez de recursos naturais;

- estejam preferencialmente inseridos em regiões sobre as quais existam dados oficiais ou estudos de disponibilidade de recursos naturais.

\section{Identificação de locais de controle}

Será igualmente necessária a utilização de um grupo de controle, com alojamentos que apresentem certificações de sustentabilidade e/ou ambientais e que, portanto, procedam a medições regulares dos consumos, mas que não adotem medidas extra para além daquelas exigidas pelas certificações. A sua seleção será efetuada por amostragem não probabilística por seleção racional.

\section{Preparação e teste das ferramentas de recolha e análise de dados}

Antes de se iniciar a recolha de dados no terreno, será útil a preparação e teste de todas as ferramentas e metodologias a usar, de forma a corrigir atempadamente eventuais erros ou falhas e a proporcionar uma recolha de dados eficiente. Para estes fins será escolhido um local de teste inicial através de 
amostragem não probabilística por seleção racional, que apresente o melhor conjunto possível das características procuradas. Será experimentada uma construção preliminar do modelo através do desenho da estrutura, compartimentos, conexões (interdependências), controles (condicionantes) e respetivos valores. Serão estabelecidos nesta altura, fruto dos testes e da pesquisa bibliográfica: $\ell$ ) se as capacidades do software são as mais indicadas ao sistema em estudo; ii) se as unidades e parâmetros de medição definidos permitem a comparabilidade dentro do sistema; iii) se existem quantidades mínimas de dados a recolher para que se obtenha significância nos resultados; iv) qual a abrangência de integração de dados (sistema mais ou menos complexo) para significância dos resultados; e, $v$ ) definição preliminar de escala de valores para resultados.

Com vista a operacionalizar o teste das ferramentas de análise serão recolhidos dados reais.

Ainda no âmbito do teste às ferramentas de recolha de dados, serão, nesta fase, testados e definidos em definitivo as unidades de medida e os instrumentos e parâmetros de medição.

\section{Unidades e instrumentos de medição}

A definição final e pormenorizada acerca das unidades de medida e dos instrumentos de medição, sua calibração e parâmetros de medição só serão possíveis após a revisão bibliográfica e a fase de testes, de forma a garantir os resultados mais confiáveis possíveis de acordo com as necessidades do modelo. No entanto, pode-se avançar provisoriamente com uma perspetiva empírica de que o recurso água será medido em Litros, a energia em Watts (seja eletricidade produzida seja a potencial a produzir), os alimentos e resíduos alimentares em quilogramas de biomassa, o solo em capacidade produtora de biomassa e a biodiversidade em dados categoriais através de indicadores (abordando apenas os recursos naturais expectáveis). Reforça-se no entanto a premissa de reservar para a fase de testes a resolução definitiva dos parâmetros e instrumentos de medição.

\section{Recolha e Tratamento dos Dados}

A recolha e tratamento de dados tem como objetivo último garantir que o fornecimento de informação ao software de modelação decorra de forma uniformizada e comparável em termos de unidades de medida e que os dados a inserir são representantes fidedignos da realidade em estudo.

Para que o modelo possa calcular o nível de sustentabilidade na gestão de recursos terá de receber valores de três grandes grupos temáticos. Os métodos a utilizar para cada uma destas categorias de dados serão expostas de seguida. A 
Metodologia de pesquisa para construção de modelo de apoio à decisão na gestão de recursos naturais em empreendimentos turísticos

categorias e escalas, através de formulações matemáticas (efetuadas com o apoio do software) que categorizam e quantificam o seu impacto, usando para tal os valores médios encontrados, de acordo com o impacto no consumo. Seguidamente será necessário fornecer a dinâmica ao sistema, criando relações funcionais em que todos os fluxos de elementos se encontrem esquematizados e todas as interdependências identificadas e quantificadas. Para a calibração e validação proceder-se-á a uma análise comparativa de diferentes conjuntos de comportamentos (equações diferenciais) dos elementos (variáveis), modelados em resposta a diferentes cenários de disponibilidade de recursos, sendo a comparabilidade assegurada por dados da realidade em estudo.

Existem várias formas possíveis de visualização dos resultados, podendo-se usar ferramentas conhecidas como CGI (Computer Generated Imagery) para gerar gráficos, imagens ou animações para uma apreensão rápida e intuitiva, ao invés das tradicionais matrizes de resultados associadas à modelação matemática pura (STROGATZ, 2007). O próprio software STELLA ${ }^{\circledR}$ já proporciona algumas ferramentas simples deste âmbito.

\section{Validação do modelo}

O modelo terá de ser validado no momento da inserção de dados para um qualquer novo empreendimento, de modo a possibilitar a previsão da sustentabilidade do consumo de recursos naturais num determinado contexto. Para tal será feita uma análise comparativa de diferentes conjuntos de soluções modeladas em resposta a diferentes cenários de disponibilidade de recursos, sendo a comparabilidade assegurada pelos dados recolhidos nos empreendimentos amostrados.

\section{Justificação da metodologia}

A modelação computacional possibilita tratar um elevado número de variáveis e apresenta-se como a melhor solução para o estudo de problemas complexos como o presente. Usa métodos numéricos com vista a efetivar simulações através de projeções temporais e/ou espaciais de fluxos de elementos (HARTMANN, 2005; LAWSON, 2006). Responde desta forma ao objetivo de análise do presente plano de pesquisa.

Dependendo do tipo de relação entre os elementos do sistema e do que se pretende simular, a modelação pode ser classificada em diferentes tipos: determinística (um resultado final para um conjunto de variáveis), variável (vários resultados finais dependentes das alterações das variáveis); dinâmica (resultados mutáveis de acordo com o comportamento intrinsecamente variável dos elementos base); e contínua (semelhante à anterior, mas dependente de eventos anteriores) (STROGATZ, 2007). Para o presente cenário de estudo existem duas 
possibilidades, a saber: a) a aplicação da modelação com características variáveis - satisfaz os objetivos de trabalho na condição de que os dados inseridos acerca das eficiências das várias soluções em estudo já incorporam, no seu desempenho médio, as respostas face às variações sazonais da disponibilidade de recursos; ou, b) a aplicação de modelação com características dinâmicas - em que a sazonalidade da disponibilidade de recursos é inserida diretamente no sistema. A primeira destas hipóteses apresenta-se como aquela que, de forma mais simples, permitirá a posterior migração do modelo para a ferramenta de apoio à decisão. No entanto, uma decisão final fica reservada para a fase de testes a efetuar.

A metodologia de recolha de dados no seu todo pode ser classificada como mista, em que os aspetos qualitativos incidem sobretudo sobre a categorização de elementos, através de observação estruturada e pesquisa documental, existindo ainda o recurso a indicadores, e a valores quantitativos sobre dados numéricos de desempenho, recorrendo à observação estruturada com medição e inquéritos por questionário. Será ainda baseada numa abordagem não experimental, uma vez que se pretendem dados que reflitam a realidade de forma direta, reservando o papel de interpretação de significados das variáveis para o software de modelação.

As amostragens a realizar serão não probabilísticas por seleção de casos típicos (RAMOS, 2010). Tal deve-se ao fato de as técnicas e tecnologias de gestão de recursos naturais que melhor se adaptam a cenários de escassez não se encontrarem disseminadas pela totalidade dos empreendimentos turísticos, nem existir nenhum segmento ou tipologia que agrupe empreendimentos por essa característica. Com base na definição de características preferenciais dos locais para estudo, serão selecionados casos típicos para recolha de dados, assim como para os casos de estudo para a comparação final.

\section{Ferramenta de apoio à decisão e comparação de estudos de caso}

A disponibilização do modelo de previsão ao público interessado será feita através de um interface que proporcione uma fácil inserção dos dados pedidos, assim como uma visualização dos resultados através de gráficos e informação de fácil apreensão (ver Figura 3). Este objetivo será facilitado com a atribuição de uma escala de valor, a estudar, para cada resultado. Os resultados deverão ser especificados por recurso natural, de forma a facilitar sugestões para melhoria. Esta ferramenta será ainda a base para um estudo comparado de boas práticas. Para estes estudos de casos serão selecionados empreendimentos situados em regiões turísticas portuguesas e brasileiras que possam servir de exemplos paradigmáticos de gestão, que traduzam realidades distintas tanto ao nível dos territórios e dos recursos disponíveis, como do tipo de turistas e das práticas habituais de gestão. 
Metodologia de pesquisa para construção de modelo de apoio à decisão na gestão de recursos naturais em empreendimentos turísticos

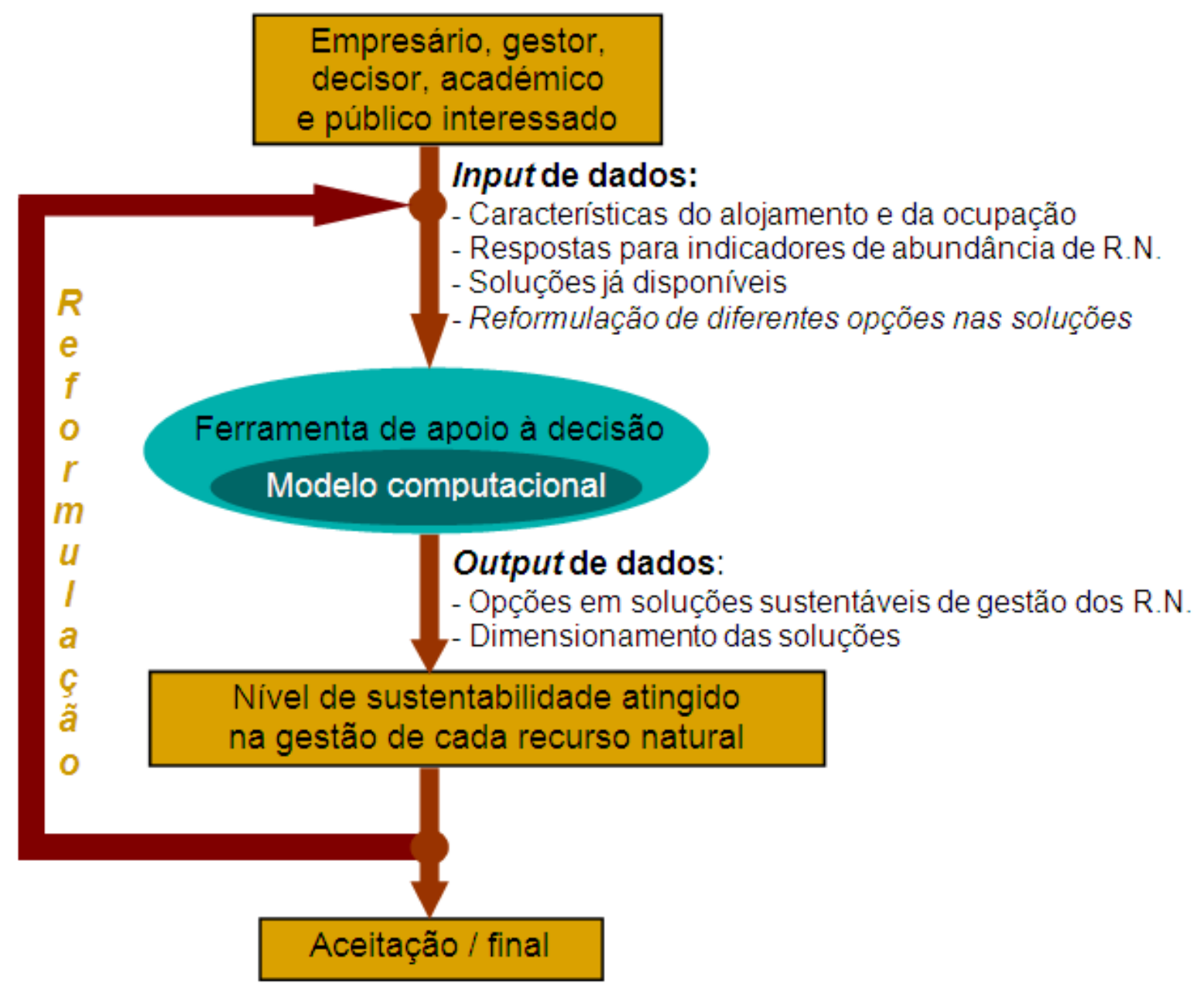

Figura 3: Objetivos e processos de funcionamento da ferramenta de apoio à decisão.

Figure 3: Objectives and operating procedures of the decision support tool.

\section{Aspetos Éticos}

Existem alguns cuidados éticos a ter, em termos de consentimento e privacidade, ao nível da implementação das ferramentas de recolha de dados e, consequentemente, ao nível do tratamento e publicação de dados (RAMOS, 2010).

Não são expectáveis impactos éticos e sociais significativos no decorrer da pesquisa, uma vez que os objetos de estudo não são sujeitos humanos. Em termos de integridade do investigador, este deverá acautelar uma condução ética, coerente e verificável sobre todos os aspetos relacionados com a recolha, tratamento e análise de dados, assim como no âmbito das publicações 
resultantes.

\section{Resultados Esperados}

Espera-se, como resultado final, que o modelo seja funcional a partir das realidades estudadas e que, incorporando a capacidade das soluções existentes, faça a sua integração para novos casos em análise, de forma a calcular respostas ao consumo de recursos naturais minimizando os impactos negativos no território e nas populações.

Pretende-se, ainda, que esta capacidade preditiva do modelo seja traduzida numa ferramenta de apoio à decisão a disponibilizar ao público e às instituições interessadas.

Produzir-se-ão conclusões acerca das estratégias de gestão sustentável de recursos naturais no turismo e nos alojamentos turísticos e da promoção de uma sustentabilidade regional mais eficiente, com o apoio de estudos de caso selecionados em Portugal e no Brasil.

Os resultados alcançados e as propostas consequentes serão colocados em forma de tese bem como de publicações em revistas científicas com "referee".

\section{Referências bibliográficas}

AYALA, H. Ecoresort: a 'green' masterplan for the international resort. Management, v.14, n.3, pp.351-374, 1995.

BUCKLEY, R. Environmental Impacts. In: WEAVER, D. (ed). The Encyclopedia of Ecotourism. Wallingford, UK: CABI Publishing, 2001.

CUNHA, M.; PINHEIRO, L.; AFONSO, P.; SOUSA, J. Modelos de Apoio à Decisão para o Planeamento e Gestão de Sistemas Regionais de Drenagem e Tratamento de Águas Residuais. In: Anais do III Congreso Ibérico sobre Gestión y Planificación del Agua, 13 a 17 de Novembro. Sevilla: Fundación Nueva Cultura del Agua, 2002. Disponível em: <http://servicio.us.es/ciberico/ archivos word/106b.doc>. Acesso em 18/01/2011.

DIAS, J.A.; POLETTE, M.; CARMO, J.A. A Ocupação e Exploração do Litoral. Reflexões para um Desenvolvimento Sustentável. Gestão Costeira Integrada, v.8, n.1, pp.5-7, 2008.

FRAME, B.; BROWN, J. Developing post-normal technologies for sustainability. Ecological Economics, v.65, n.2, pp.225-241, 2008.

GASPARATOS, A. Embedded value systems in sustainability assessment tools and their implications. Journal of environmental management, v.91, n.8, pp.1613-22, 2010.

GOSSLING, S.; HANSSON, C.B.; HÖRSTMEIER, O.; SAGGEL, S. Ecological 
Metodologia de pesquisa para construção de modelo de apoio à decisão na gestão de recursos naturais em empreendimentos turísticos

footprint analysis as a tool to assess tourism sustainability. Ecological Economics, v.43, n.2-3, pp.199-211, 2002.

GRAULICH, K. EcoTopTen: Innovations for sustainable consumption. EEDAL, v.6, p.21-23, 2006.

HAAPIO, A.; VIITANIEMI, P. A critical review of building environmental assessment tools. Environmental Impact Assessment Review, v.28, n.7, pp.469-482, 2008.

HALPENNY, E. Islands and Coasts. In: WEAVER, D. (ed). The Encyclopedia of Ecotourism. Wallingford, UK: CABI Publishing, 2001.

HARTMANN, S. The World as a Process: Simulations in the Natural and Social Sciences. Unpublished, 2005. Disponível em: <http://philsciarchive.pitt.edu/id/eprint/2412>. Acesso em: 07-12-2010.

HUNTER, C.; SHAW, J. The ecological footprint as a key indicator of sustainable tourism. Tourism Management, v.28, n.1, pp.46-57, 2007.

JANÉR, A. Turismo Sustentável e Certificação - Avanços no Cenário Internacional. In: 6 FÓRUM INTERNACIONAL DE TURISMO SUSTENTÁVEL, 11 de Setembro, São Paulo: Instituto EcoBrasil, 2009. Disponível em: <http:// www.ecobrasil.org.br/publique/media/EcoBrasil\%20-\%20Ariane\%20Janer\%20-\% 20FITS\%202009.pdf>. Acesso em: 02/09/2010.

LAWRENCE, E.;.VAN LOON, B. Fenómenos Atmosféricos. Lisboa: Plátano Edições Técnicas, 2000.

LAWSON, S. Computer Simulation as a Tool for Planning and Management of Visitor Use in Protected Natural Areas. Journal of Sustainable Tourism, v.14, n.6, pp.600-617, 2006.

LIBURD, J.; CARLSEN, J.; EDWARDS, D.; FORDE, P. Innovation for Sustainable Tourism: International Case Studies. Esbjerg, Denmark: BEST Education Network, 2007.

NESS, B.; URBELPIIRSALU, E.; ANDERBERG, S.; OLSSON, L. Categorising tools for sustainability assessment. Ecological Economics, v.60, n.3, pp.498-508, 2007.

OSLAND, G.; MACKOY, R. Ecolodge Performance Goals and Evaluations. Journal of Ecotourism, v.3, n.2, pp.109-128, 2004.

PEREIRA, A.R.; ZÊZERE, J.L.; MORGADO, P. Os Recursos Naturais em Portugal: Inventariação e Proposta de um Modelo Geográfico de Avaliação. In: Anais do X Colóquio Ibérico de Geografia, 22 a 24 de Setembro. Évora: Universidade de Évora, 2005. Disponível em: <www.apgeo.pt/files/docs/ CD X Coloquio Iberico.../089.pdf >. Acesso em: 18/01/2011. 
RAMOS, S. Apontamentos da disciplina de Teoria e Métodos de Investigação II. Coimbra: Universidade de Coimbra, 2010.

ROSS, S. Ecotourism: towards congruence between theory and practice. Tourism Management, v.20, n.1, pp.123-132, 1999.

SINGH, R.K.; MURTY, H.R.; GUPTA, S.K.; DIKSHIT, A.K. An overview of sustainability assessment methodologies. Ecological Indicators, v.15, n.1, pp.281 -299, 2012.

STIJNS, J. Natural resource abundance and human capital accumulation. World Development, v.34, n.6, pp.1060-1083, 2006.

STROGATZ, S. What is your dangerous idea? The End of Insight. UK: HarperCollins, 2007.

SWARBROOKE, J. Sustainable Tourism Management. Oxon, UK: CAB International, 1999.

TIMAH, E.A.; AJAGA, N.; TITA, D.F.; NTONGA, L.M.; BONGSIYSI, I.B. Demographic pressure and natural resources conservation. Ecological Economics, v.64, n.3, pp.475-483, 2008.

TURISMO DE PORTUGAL. (s.d.). Disponível em: <http:// www.turismodeportugal.pt/Portugu\%C3\%AAs/AreasActividade/qualificacaooferta/ empreendimentoseactividades/empreendimentos/Pages/EmpreendimentosTur\% C3\%ADsticos.aspx>. Acesso em: 18/01/2010.

WCED. Our Common Future. Oxford: Oxford University Press, 1987. Disponível em: <http://www.worldinbalance.net/agreements/1987-brundtland.html>. Acesso em: 21/02/2011.

WEAVER, D.; LAWTON, L. Twenty years on: The state of contemporary ecotourism research. Tourism Management, v.28, n.5, pp.1168-1179, 2007.

WOOD, M. Ecotourism: Principles, Practices \& Policies for Sustainability. Paris: United Nations Publication, 2002.

WTO. Sustainable Development of Tourism - Conceptual definition. World Tourism Organization, 2004. Disponível em: <http://www.world-tourism.org/ sustainable/concepts.htm>. Acesso em: 7/12/2010.

\section{Nota dos Editores:}

${ }^{1}$ Este artigo consiste efetivamente numa "nota de pesquisa", ("Projecto de Investigação", em Portugal)". Os editores decidiram pela publicação por se tratar de um trabaIho de caráter metodológico bem elaborado, que contribui para o desenvolvimento da área de Ecoturismo. Os autores se comprometeram a publicar, nesta Revista, os futuros resultados do modelo elaborado, assim que a metodologia for aplicada. 
Agradecimentos: Este artigo é derivado de plano de trabalho para Doutoramento em Turismo, Lazer e Cultura - Universidade de Coimbra, sendo financiado por Fundos Nacionais através da FCT - Fundação para a Ciência e a Tecnologia no âmbito da Bolsa de Doutoramento «SFRH/BD/74171/2010».

João Miguel Mendes Silveira: CEGOT - Centro de Estudos de Geografia e Ordenamento do Território, Universidade de Coimbra, Coimbra, Portugal.

Email:m.mendes.silveira@gmail.com

Link para o currículo: https://docs.google.com/open?id=0B0YzywohuF6 bDVMZnNJTEowNEk

Lúcio José Sobral Cunha: CEGOT - Centro de Estudos de Geografia e Ordenamento do Território, Universidade de Coimbra, Coimbra, Portugal.

Email: luciogeo@ci.uc.pt

Link para o currículo: http://apps.uc.pt/mypage/files/luciogeo/200

Data de submissão: 28 de fevereiro de 2012

Data de recebimento de correções: 30 de abril de 2012

Data do aceite: $1^{\circ}$ de maio de 2012

Avaliado anonimamente 